\title{
Can the Sharia-Based Islamic Stock Market Returns be Forecasted Using Large Number of Predictors and Models?
}

\author{
Rangan Gupta $^{\mathrm{a}}$, Shawkat Hammoudeh ${ }^{\mathrm{b}}$, Beatrice D. Simo-Kengne ${ }^{\mathrm{c}}$, Soodabeh Sarafrazi ${ }^{\mathrm{d}}$
}

\begin{abstract}
.
This study employs fourteen global economic and financial variables to predict the return of the Islamic stock market as identified by the Dow Jones Islamic stock market. It implements alternative forecasting methods and allows for nonlinearity in the multivariate predictive regressions by estimating time-varying parameter models. All the methods fail to forecast the returns of the Sharia-based DJIM index over the out-of-sample period. The forecasts are weak at best, with only four predictors the three-month Treasury bill rate, inflation, oil price and return on the S\&P500 index outperforming the benchmark autoregressive model of order one. The study suggests that the DJIM return is best predicted by an AR(1) model, and that future research should aim at analysing whether the performance of the linear autoregressive model can be improved by using nonlinear methods
\end{abstract}

Keywords: DJIM; forecasting methods; out-of-sample forecasts; benchmark model

JEL: C58, G11

\section{Introduction}

\footnotetext{
${ }^{a}$ Department of Economics, University of Pretoria, Pretoria, South Africa. Email: rangan.gupta@up.ac.za.

b Corresponding author. LeBow College of Business, Drexel University, Philadelphia, USA. Email: hammousm@drexel.edu.

c Department of Economics, University of Pretoria, Pretoria, South Africa. Email: beatrice.simo_kengne@up.ac.za.

${ }^{\mathrm{d}}$ LeBow College of Business, Drexel University, Philadelphia, USA. Email: ss992@ drexel.edu.
} 
Forecasting equity market returns is important in the financial markets since it results have significant influence on investment decisions, risk management and market regulations. Many researchers have endeavoured to find the correct answer for the question of how to forecast stock returns the best way possible. Many variables, methodologies and forecast horizons have been used to achieve this goal, but no particular consensus has been reached during the last two decades. Some studies of conventional stock market returns have found that these returns are predictable using some economic variables such as interest rates, inflation and industrial production. Others find some forecasting success by using financial ratios such dividend yield and earning-price ratio. More eclectic forecasting methods have been used recently.

To our knowledge, no studies have attempted to forecast the returns of Islamic stock markets. As difficult it is to forecast the returns of conventional markets, it should be more cumbersome to forecast the returns of the Islamic markets. The Islamic and conventional markets differ in several ways. The Islamic markets prefer growth and small cap stocks, while conventional markets favour value and mid cap stocks. Furthermore, Islamic finance restricts investments in some industries such alcohol, tobacco, rearms, gambling, nuclear power and military-weapons activities. It also restricts speculative financial transactions such as financial derivatives which have no underlying real transactions like futures and options, government debt issues with a fixed coupon rate, and hedging by forward sale, interest-rate swaps and any other transactions involving items not physically in the ownership of the seller (e.g., short sales).

Nevertheless, forecasting the Islamic stock markets is valuable and timely. The markets that follow the Sharia-based principles have grown $500 \%$ in the last five years to reach $\$ 1.6$ trillion in 2013 (Hammoudeh et al., 2013), rising from \$1.46 in 2012 (Vizcaino, 2013). Despite this fast growth, Islamic finance accounts for only $1 \%$ of all global finance while 
Muslims constitutes $25 \%$ of the world's population, which is equivalent to 1.6 billion people. Therefore, several governments and policy makers identify Islamic finance as a key global growth area. At the $5^{\text {th }}$ Izmir Economic Congress which was held in 2013, the president of the World Bank strongly lent his support to Islamic finance. In London in the same year, the British prime minister announced that a new Islamic Index will be created on the London Stock Exchange and that there are real plans afoot for the UK Government to issue Islamic bonds known as sukuks ${ }^{1}$. The government of Dubai also declared its support for Islamic finance earlier this year. London, Kuala Lumpur and Dubai are currently competing for preeminence as the prominent Islamic finance center.

Against this backdrop, the objective of this paper is to make an attempt to forecast returns on the Dow Jones Islamic Stock (DJIM) Index using fourteen possible predictors, based on monthly data covering an out-of-sample horizon of 2007:M1-2013:M6, given an insample of 1999:M1-2006:M12. Following the extant literature on forecasting stock returns, we start with individual predictive regressions, which includes each of the fourteen predictors in turn, in a bivariate set-up with the dependent variables being the DJIM returns. Predictability is weak at best, with only four (the three-months Treasury bill rate, inflation, oil price and return on the S\&P500) of the predictors outperforming the benchmark autoregressive model of order one. Given this, we looked at combining information from all the fourteen predictors simultaneously by using alternative forecast combination methods, and linear and nonlinear (time-varying) multivariate predictive regressions. Since the timevarying models tend to get overparameterized quickly, we use the Bayesian shrinkage methods to overcome this issue. Whether the method leads to forecasts based on forecast combinations or linear and nonlinear multivariate predictive regressions, the alternative models fail to outperform the AR(1) model. Finally, realizing the possibility of datamining as

\footnotetext{
${ }^{1}$ These are the Islamic equivalent of short-term bonds. Sukuk securities are structured to comply with the Islamic law and its investment principles which prohibit the charging, or paying of interest. Little of these securities enter the secondary market. http://en.wikipedia.org/wiki/Sukuk.
} 
we use multiple predictors, we use a bootstrap method to compute datamining critical values for the forecast comparison tests between the bivariate predictive regressions and the $\mathrm{AR}(1)$ model. We find that the limited predictability of the four predictors listed above, disappears as well. Our results thus tend to lean toward the DJIM market being efficient.

The rest of the paper is organized as follow. Section 2 provides a brief review of the literature related to forecasting stock market returns. Section 3 presents the methods which are used in forecasting the DJIM returns. Section 4 discusses the data and Section 5 provides the result. Section 6 concludes the paper.

\section{Review of the literature}

A number of studies have used a range of variables in an attempt to predict stock market returns. Ball (1978), Rozeff (1984), Shiller (1984), Fama and French (1988a and b), Hodrick (1992), Menzly, Santos, and Veronesi (2004) use the dividend yield to forecast stock returns. Kothari and Shanken (1997), and Pontiff and Schall (1998) employ the book-tomarket ratios. Lintner (1975), Famaand Schwert (1977), and Fama (1981) utilize economic variables such as the inflation rate. Balvers, Cosimano and McDonald (1990) and Schwert (1990) use industrial production. Campbell (1987), Hodrick (1992), and Ang and Bekaert (2007) employ short-term interest rates.

Among these forecasting factors, the dividend yield and the earning-price ratio are judged to be the best candidates since they both demonstrate relationships to stock market returns as they have the price in the denominator. As indicated earlier, Islamic finance imposes limits on financial ratios because they are related to interest rates, debt and leverage which can be related to bubbles and speculative behavior. This makes forecasting Islamic stock market returns more challenging relative to their conventional counterparts. 
Recent forecasting techniques of conventional stock markets include neural network, data mining, Markov model and neuro-fuzzy system. In those techniques, the firms' characteristics are not taken into consideration in the forecasting process.

The literature on the relations between the Islamic and conventional stock markets is very mixed. There are studies that support the dichotomy hypothesis for these markets (Hakim and Rashidian, 2002; Dewi and Ferdian, 2010) and contend that the Islamic markets have not been affected much by the recent global financial crisis (Chapra, 2008; Dridi and Hassan, 2010; Arouri et al., 2013) compared to their conventional counterparts. Others find a unidirectional relationship between these markets. More recently, using asymmetric and nonlinear techniques, some studies find a bidirectional relation (Ajmi et al., 2014). Thus, it is not clear if the conventional markets can be used to forecast Islamic markets.

\section{Methodology}

Several forecasting approaches exist in the financial literature. To our knowledge, no forecasting approaches have been used to forecast the Islamic stock market returns. Based on various theoretical considerations, an array of fourteen predictors has been selected to forecast the DJIM returns, using predictive regressions with a particular focus on the out-ofsample predictability. The recursive scheme used to test the out-of-sample predictability for DJIM returns is based on the following predictive regression framework ${ }^{2}$ :

$$
y_{t+1}^{k}=\alpha+\beta \cdot z_{t}+\gamma \cdot y_{t}+\mu_{t+1}^{k}
$$

where the total sample of $T$ observations is divided into the in-sample 1990:M1 to 2006:M12 period and the out-of-sample 2007:M1 to 2013:M6 period. The in-sample observations span

\footnotetext{
${ }^{2}$ The lag length of one is selected based on the Schwartz Information Criterion (SIC).
} 
the first $R$ observations for the series $y_{t}$ and $z_{t}$,while the out-of-sample spans the last $P$ observations for $y_{t}$ and $z_{t}$. The first unrestricted predictive regression model specified in Equation (1) for the out-of-sample forecast is generated as in Rapach et al. (2005). First, we estimate the unrestricted predictive regression model using the OLS, with the data available through period R. The OLS estimates in Equation (1) therefore become $\hat{\alpha}_{1, R}, \hat{\beta}_{1, R}$ and $\hat{\gamma}_{1, R}$. Using the OLS parameter estimates from the predictive regression in Equation (1) and the series $y_{R}$ and $z_{R}$, we construct a forecast for $y_{R+1}^{k}$ based on the unrestricted predictive regression model using $\hat{y}_{1, R+1}^{k}=\hat{\alpha}_{1, R}+\hat{\beta}_{1, R} \cdot z_{R}+\hat{\gamma}_{1, R} \cdot y_{R}$. The forecast error is therefore denoted by $\hat{\mu}_{1, R+1}^{k}=y_{R+1}^{k}-\hat{y}_{1, R+1}^{k}$. Second, we generate the forecast error for the restricted model in a similar manner, except we set $\beta=0$, using the data available to period $\mathrm{R}$ in order to obtain the OLS estimates in Equation (1), $\hat{\alpha}_{0, R}$ and $\hat{\gamma}_{0, R}$. We construct a forecast for $y_{R+1}^{k}$ based on the restricted predictive regression model, using $\hat{y}_{0, R+1}^{k}=\hat{\alpha}_{0, R}+\hat{\gamma}_{0, R} \cdot y_{R}$. The forecast errors corresponding to the restricted predictive model are denoted by $\hat{\mu}_{0, R+1}^{k}=y_{R+1}^{k}-\hat{y}_{0, R+1}^{k}$

In order to generate a second set of forecasts, we update the above procedure one period using the data available through period $R+1$. That is, we estimate both the unrestricted and the restricted predictive regression models using data available through period $R+1$ and we use these parameter estimates and the observations for $y_{R+1}$ and $z_{R+1}$ in order to form unrestricted and restricted model forecasts for $y_{R+2}^{k}$ and their forecast errors, $\hat{\mu}_{1, R+2}^{k}$ and $\hat{\mu}_{0, R+2}^{k}$. We repeat this process for the entire available sample, resulting in two sets of 
$T-R-K+1$ recursive forecast errors: $\left\{\hat{\mu}_{1, t+1}^{k}\right\}_{t=R}^{T-k}$ for the unrestricted predictive regression model and $\left\{\hat{\mu}_{0, t+1}^{k}\right\}_{t=R}^{T-k}$ for the restricted model. We then compare the out-of-sample forecasts from the restricted and the unrestricted predictive forecast models. If the unrestricted model forecasts are superior to the restricted model forecasts, then variable $z_{t}$ improves the out-ofsample forecast of $y_{t+1}^{k}$ relative to the first-order autocorrelation (AR) benchmark model which excludes $z_{t}$. It has been shown that Theil's $\mathrm{U}$ statistic, which is the ratio of the unrestricted model's forecast mean-squared error (MSE) to the restricted model's forecast MSE, is a simple metric for comparing forecasts. By definition, Theil's U compares the prediction from a given model to a random walk model. Even though we include a lagged stock return term in the benchmark model, we still use the term Theil's U. If the MSE for the unrestricted model forecast is less than the MSE for the restricted model forecast, then $U<1$. To formally test for the superiority of the unrestricted model forecast to the restricted model forecast, we followed the MSE-F statistics provided in McCracken (2004). The MSE-F is the variant of the Diebold and Mariano (1995) and West (1996) statistics designed to test for equal predictive ability. We use the MSE-F to test the null hypothesis that the unrestricted model forecast MSE is equal to the MSE for the restricted model against the one-sided (upper-tail) alternative that the unrestricted model forecast MSE is less than the MSE forecast for the restricted model. The MSE-F statistic is based on the loss differential

$$
\hat{d}_{t+k}^{k}=\left(\hat{\mu}_{0, t+1}^{k}\right)^{2}-\left(\hat{\mu}_{1, t+1}^{k}\right)^{2}
$$

Let: $\bar{d}=(T-R-k+1)^{-1} \sum_{t=R}^{T-k} \hat{d}_{t+1}^{k}=\hat{M S E_{0}}-\hat{M S E_{1}}$ 
where: $\hat{M S E} E_{i}=(T-R-k+1)^{-1} \sum_{t=R}^{T-k}\left(\mu_{i, t+1}^{k}\right)^{2}, i=0,1$

The McCracken (2004) MSE-F statistic is therefore given by:

$M S E-F=(T-R-k+1) \cdot \bar{d} / M S E_{1}$

A significant $M S E-F$ indicates that the unrestricted model forecasts are statistically superior to those of the restricted model.

\section{Data}

The analysis in this paper is based on monthly data, mostly sourced from the Federal Reserve Economic Database and Bloomberg ${ }^{3}$. Other sources include the International Financial Statistics of the International Monetary Fund and http:www.policyuncertainty.com/index.html.Besides the Dow Jones Islamic market (DJIM) index, the return of which is what we forecast, there are the real and financial predictors: the US financial stress index maintained by the Kansas City Federal Reserve, the US economic policy uncertainty measure ${ }^{4}$, the US default spread, the US industrial production, the nominal trade weighed US dollar index, the US short-term interest rate (three-months Treasury bills rate), the US stock market index, the US inflation, the European stock market index, the Asian stock market index, the oil price, the US employment rate, the US consumer sentiment index maintained by the University of Michigan and the US stock market volatility. The explanatory variables therefore comprise both demand and supply determinants of the DJIM index. They also include two important measures of the economic and financial risks: the US economic policy uncertainty and Kansas City Fed's financial stress index ${ }^{5}$. Furthermore, the

\footnotetext{
${ }^{3}$ http:www.blomberg.com/markets/stocks/world-indexes/.

${ }^{4}$ For more detailed information regarding the construction of the economic policy uncertainty indexes, the reader is referred to Baker et al. (2013).

${ }^{5}$ http://www.kansascityfed.org/research/indicatorsdata/kcfsi/
} 
interest rate captures the opportunity cost of holding the DJIM instead of investing in other return-yielding assets, while the oil price and employment account for possible changes in economic activity and business cycles.

All variables are obtained in their seasonally adjusted forms and the variables that are available at higher frequencies than a month are averaged out over the respective days to obtain monthly figures. Standard unit root tests are performed on all the variables to test for stationarity ${ }^{6}$. In the cases where the variables are not stationary, transformations similar to those used by Koop and Korobilis (2012) are applied to ensure stationarity of all the variables. The different transformation codes and the detailed descriptions of the data, including their sources, are listed and defined in Table 1 and Table A1 in the Appendix. The oil price has by far the highest historical volatility as defined by the standard deviation (i.e., 5.421), followed by the US financial stress index (1.138). The lowest volatility is bestowed on the US employment (0.002). Interestingly, the return on the DJIM has generally low contemporaneous correlations with nine out of the fourteen predictors; having high correlations with all the three conventional stock market indexes: $0.931,0.888$ and 0.845 for SP500, SPEU and SPAS50, respectively. It is worth nothing that the correlations with economic and financial risk measures are negative as expected; that is, -0.346 and -0.174 for the financial stress index and the economic policy uncertainty, respectively. Moreover, most of the variables are negatively skewed with relatively high kurtosis, except the industrial production, the consumer sentiment and the volatility of the stock market. Importantly, all the variables do not have a normal distribution as suggested by Jarques-Bera statistics.

Figure A1 in the appendix plots the untransformed variables, while the transformed variables are plotted in Figure A2. The sample period, from 1999:M1 to 2013:M6, is chosen based on the availability of the data on all variables (DJIM and the fourteen predictors). The

\footnotetext{
${ }^{6}$ The unit root test results are available upon request from authors.
} 
out-of sample period ranges from 2007:M1 to 2013:M6, which is a normal choice given the increased volatility of the DJIM returns since the beginning of 2007, as depicted in Figure1.

\section{Empirical Results}

The empirical results analyse the forecast performance of the predictive regression, our preferred model, using the mean squared errors (MSE) over the out-of sample period 2007:M1 to 2013:M6. We consider the following forecast horizons: 1(h=1), $3(h=3), 6(h=6)$, $9(\mathrm{~h}=9)$ and $12(\mathrm{~h}=12)$ months. The model includes an intercept and one lag of the dependent variable (DJIM) selected by the Schwartz information criterion. As provided in Table 2, the main predictors of the DJIM return appear to be SP500 $(h=3)$, TBILL ( $h=9$ and 12), INF $(\mathrm{h}=6,9,12)$ and $\mathrm{OP}(\mathrm{h}=6)$ which are major cyclical economic and financial variables related to the U.S. economy. More specifically, the predictive regression suggests that INF (inflation) has less predictive power than OP or the NITWIT (though significant at the 10\% level) at a 6month horizon while at longer horizons $(h=9,12)$, INF has more predictive power than TBILL. It is surprising to have the TBill variable as a predictor of the Sharia-compliant Islamic stock market which prohibits using interest and restricts the interest-bearing investments to be less than a certain level.

In general, the predictability of the DJIM returns is weak at best. To try to improve the forecast performance of the individual predictors, we implement alternative forecasting methods that allow one to incorporate the information content of each of the predictors simultaneously. Firstly, we look at alternative methods of forecast combinations, namely mean, median, trimmed mean, discounted mean square forecast error, cluster, principal components and bagging (bootstrap aggregating). Secondly, we use all the predictors simultaneously or a set of factors extracted from all the predictors in the predictive regression 
framework. That is, we construct forecasts based on multiple predictors-based predictive regressions, unlike the bivariate predictive regressions discussed above.

In addition, we allow for nonlinearity in the multivariate predictive regressions by estimating time-varying parameter models. The time-varying parameter approach has the advantage to allow the parameters to change over time, but may have a poor out-of sample performance in the presence of large sets of predictors. Hence, we use the Bayesian shrinkage based on the least absolute shrinkage selection operator (LASSO) (Belmonte et al., 2013), the dynamic model averaging (DMA) and the dynamic model selection (DMS) (Koop and Korobilis, 2012). In particular, the DMA combines information from a set of predictors by averaging forecast across a set of equations, while the DMS involves selecting the single model with the highest predictive power and using this to forecast. DMA and DMS are conditional on the forgetting parameters $(\alpha$ and $\lambda)$ imposed on the state equation for the models and the state equation for the parameters, respectively. Note that we also look at the Bayesian model averaging (BMA) model which is limited to static models with parameter uncertainty. It is therefore a special case of DMA where $\alpha=\lambda=1$. Interestingly, these methods fail to improve the forecast performance of the DJIM relative to the benchmark AR model as the ratio of the mean square error from these models relative to the AR(1) model always exceeds unity. Hence, we report these results in Table A2 in the Appendix of the paper.

Reverting back to the bivariate predictive regressions again, it must be noted that the usage of many variables in a predictive regression model has been shown to be questionable as the estimation results become susceptible to datamining. To circumvent this issue, a bootstrap procedure (as in Rapach et al., 2005 and Rapach and Wohar, 2006) is used to construct critical values that account for datamining. As confirmed in Table 2, when considering the datamining critical values, none of the significant MSEs (in bold) remains 
significant as their critical values (in bracket) are all less than their corresponding datamining critical values reported in the notes of Table 2.

\section{Conclusions}

This study uses fourteen global economic and financial variables to predict the return of the Islamic stock market as identified by the Dow Jones Islamic stock market (DJIM) index. It implements alternative forecasting methods that allow one to incorporate the information content of each of the predictors simultaneously. The paper also allows for nonlinearity in the multivariate predictive regressions by estimating time-varying parameter models including the use of Bayesian shrinkage based on the least absolute shrinkage selection operator (LASSO), the dynamic model averaging (DMA) and the dynamic model selection (DMS).Moreover, it also considers the following forecast horizons: $1(h=1), 3(h=3), 6(h=6)$, $9(\mathrm{~h}=9)$ and $12(\mathrm{~h}=12)$ months.

All the methods have failed to forecast the returns of the DJIM index over the forecast period 2007:M1 to 2013:M6. The forecasts are weak at best, with only four (the three-months Treasury bill rate, inflation, oil price and return on the S\&P500) of the predictors outperforming the benchmark autoregressive model of order one. This should not be totally surprising, when one contextualizes the results in terms of the international literature on the limited forecastability, in general, of the returns of conventional stock markets (see Rapach and Zhou (2013) for further details). It is more difficult to forecast returns of Islamic stock markets because those markets must comply with certain Sharia rules prescribed by Islamic scholars.

Some studies have some success in forecasting the returns of conventional stock markets using financial ratios such as the dividend yield and the earning-price ratio. However, the Sharia rules impose limits on the financial ratios which hamper their function 
as predictors in the Islamic finance industry. Moreover, Islamic finance is asset-based, asset driven and prohibits interest on transactions. This means the interest rate channel that connects the financial and real sectors and funnels monetary policy should be broken. These factors add significantly to the difficulty of forecasting returns of Islamic stock markets. With the current strong drive in developing major Islamic finance centers in London, Dubai and Kuala Lumpur and strong interest in doing research in this area, there is hope to have better understanding of the link between the conventional and Islamic markets. In this case, reaching a consensus on predictors of conventional markets may have an important bearing on predicting the Islamic financial markets.

It will be remiss if we do not raise the question of whether Islamic stock markets are efficient. This is a subject for a future research. In addition, given that our paper tends to suggest that the DJIM return is best predicted by an AR(1) model, future research would also be aimed at analysing whether the performance of the linear autoregressive model can be improved by using nonlinear (smooth or discrete regime-switching) and or nonparametric versions of the univariate autoregressive model due to the wide evidence on the existence of nonlinear data-generating process for asset returns (see for example Guidolin et al., 2009, 2010, and references cited therein). ${ }^{7}$ Note that, this will also allow one to test the predictability of the DJIM returns at the highest possible (daily) frequency.

\footnotetext{
${ }^{7}$ Note that in our time-varying models, nonlinearity is only captured between the DJIM returns and the predictors. We do not specifically model the DJIM returns as nonlinear originating from a nonlinear datagenerating process.
} 


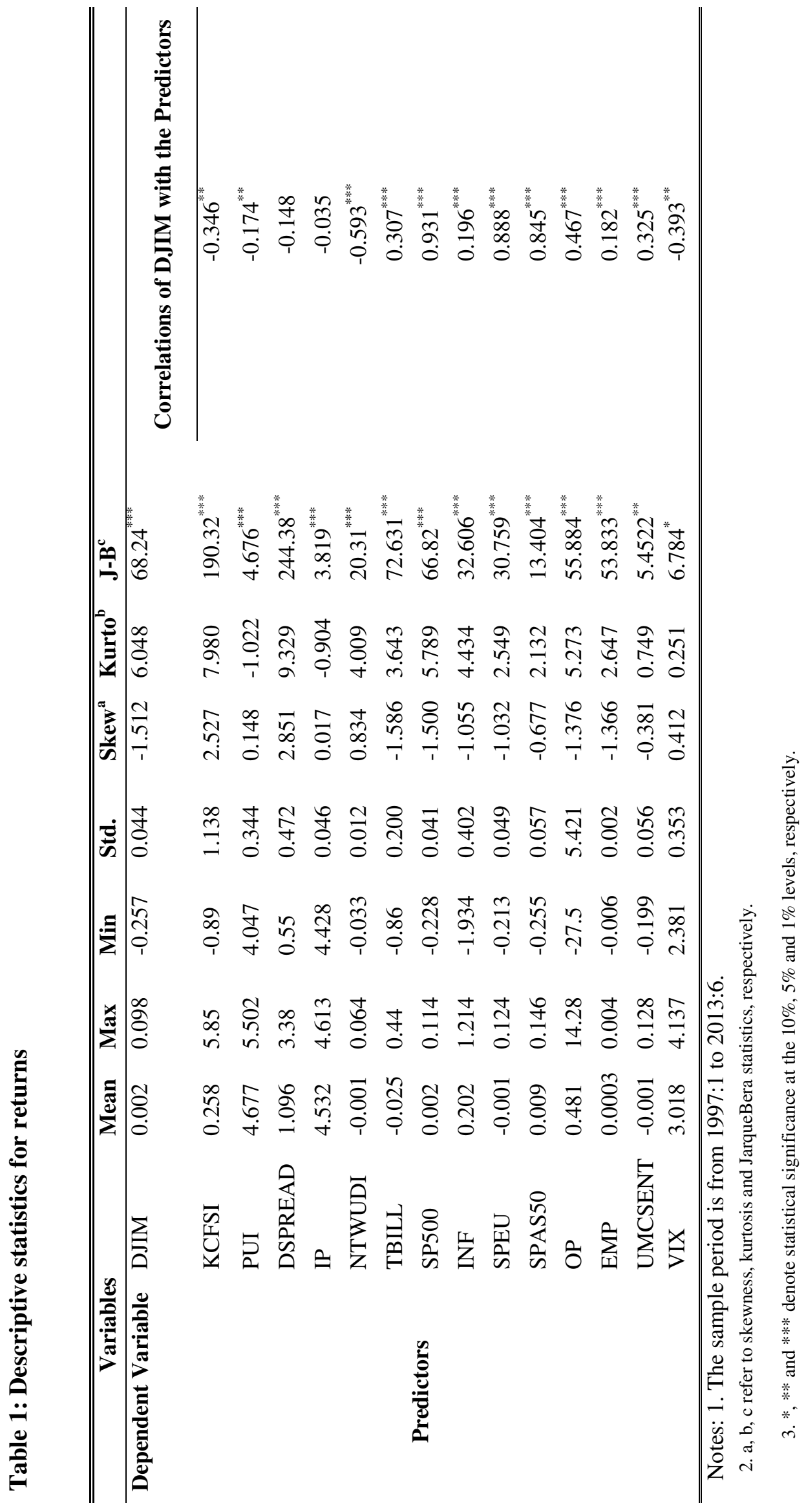


Figure 1: Growth Rate of the DJIM

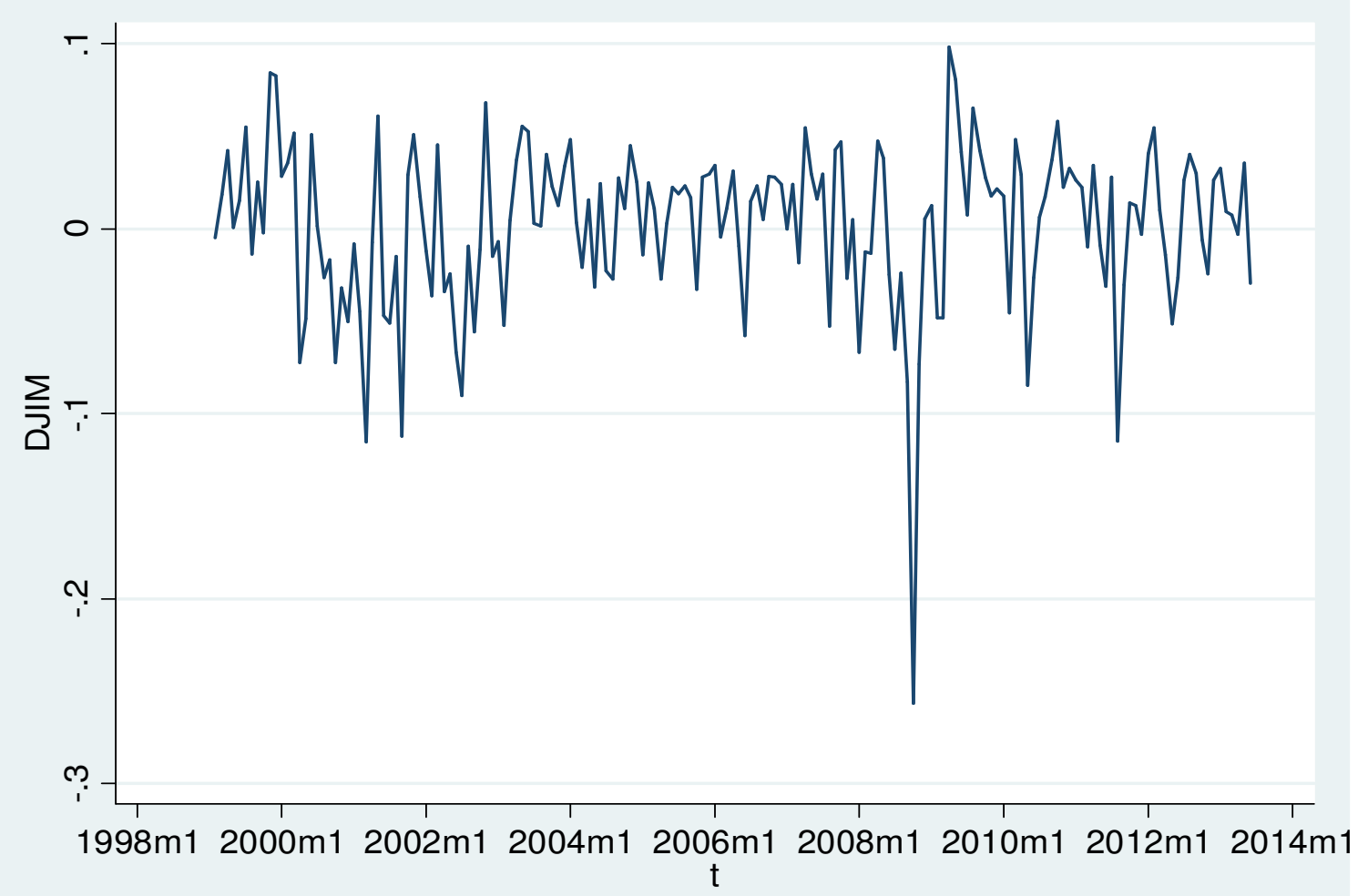


Table 2: Individual Forecasts

PREDICTORS MSE

\begin{tabular}{|c|c|c|c|c|c|}
\hline Variable & $\mathrm{H}=1$ & $\mathbf{H}=\mathbf{3}$ & $H=6$ & $\mathrm{H}=9$ & $H=12$ \\
\hline KCFSI & 1.0345 & 1.1265 & 1.4653 & 1.7023 & 1.8660 \\
\hline PUI & 1.0151 & 1.0147 & 1.0429 & 1.0786 & 1.0736 \\
\hline DSPREAD & 1.0309 & 1.1205 & 1.3966 & 1.3129 & 1.0164 \\
\hline IP & 1.0051 & 1.0068 & 1.0134 & 1.0488 & 1.1098 \\
\hline NTWUDI & 1.0246 & 1.0050 & 1.0065 & 1.0075 & 1.0337 \\
\hline TBILL & 1.0123 & 1.0113 & 1.0092 & $\begin{array}{l}\mathbf{0 . 9 7 5 5 ^ { * }} \\
{[3.5011]}\end{array}$ & $\begin{array}{l}\mathbf{0 . 9 4 9 5}^{* * *} \\
{[7.2024]}\end{array}$ \\
\hline SP500 & 0.9953 & $\begin{array}{l}\mathbf{0 . 9 8 5 6}{ }^{* *} \\
{[2.2017]}\end{array}$ & 0.9949 & 1.0089 & 1.0156 \\
\hline INF & 1.0103 & 1.0055 & $\begin{array}{l}\mathbf{0 . 9 7 4 2}^{* *} \\
{[3.8589]}\end{array}$ & $\begin{array}{l}\mathbf{0 . 9 7 9 2}^{* * *} \\
{[2.9641]}\end{array}$ & $\begin{array}{l}\mathbf{0 . 9 7 7 8} 8^{* * * *} \\
{[3.0344]}\end{array}$ \\
\hline SPEU & 1.0137 & 0.9997 & 1.021 & 1.0461 & 1.0565 \\
\hline SPAS50 & 1.009 & 1.0033 & 1.0002 & 1.0023 & 0.9974 \\
\hline $\mathrm{OP}$ & 1.0228 & 1.03 & $\begin{array}{l}\mathbf{0 . 9 8 7 8}^{*} \\
{[1.7913]}\end{array}$ & 1.0044 & 1.014 \\
\hline EMP & 1.0218 & 1.089 & 1.2355 & 1.2622 & 1.1963 \\
\hline UMCSENT & 1.0159 & 1.0186 & 1.0037 & 0.9977 & 0.9979 \\
\hline VIX & 0.9996 & 0.9996 & 1.0351 & 1.0691 & 1.0918 \\
\hline
\end{tabular}

Notes: The entries are the ratio of individual MSEs relative to the AR benchmark MSE so that a ratio above unity indicates that the individual forecast is less accurate than the AR benchmark forecast in terms of MSE. All forecast are recursive and the MSEs are computed over the period 2007:1-(2013:6-h).*,** and *** indicate significance at the $10 \%, 5 \%$ and $1 \%$ level, respectively. However, when considering the datamining critical values, none of the significant MSEs (in bold) remains significant as they are all less than their corresponding critical values in bracket. The datamining critical values are as follow:

- $\quad 2.9755,3.9740$ and 6.6578 at the $10 \%, 5 \%$ and $1 \%$ level of significance, respectively for horizon 1 ;

- $\quad 7.0979,10.1392$ and 15.5414 at the $10 \%, 5 \%$ and $1 \%$ level of significance, respectively for horizon 3 ;

- $\quad 12.3165,16.9424$ and 30.2634 at the $10 \%, 5 \%$ and $1 \%$ level of significance, respectively for horizon 6 ;

- $\quad 19.5824,25.8538$ and 50.2269 at the $10 \%, 5 \%$ and $1 \%$ level of significance, respectively for horizon 9;

- $\quad 23.8122,30.8312$ and 61.4858 at the $10 \%, 5 \%$ and $1 \%$ level of significance, respectively for horizon 12 ; 


\section{References}

Ajmi, A. N.., Hammoudeh, S., Nguyen, D. K and Sarafrazi, S. "How strong are the causal relationships between Islamic stock markets and conventional financial systems? Evidence from linear and nonlinear tests."Journal of International Financial Markets, Institutions and Money (forthcoming).

Ang, A., Bekaert, C., 2007, Stock return predictability: Is it there?,Review of financial studies, 20(3), 651-707.

Arouri, M. E., Ameur, H. B., Jawadi, N., Jawadi, F and Louhichi, W., 2013, Are Islamic finance innovations enough for investors to escape from a financial downturn? Further evidence from portfolio simulations, Applied Economics, 45, 3412-3420.

Bai, J., NG, S., 2002, Determining the number of factors in approximate factor models. Econometrica, Econometric Society, 70(1), 191-221

Baker, S.R., Bloom, N., S. J. Davis, 2013, Measuring economic policy uncertainty, Available for download from: www.PolicyUncertainty.com.

Ball, R., 1978, Anomalies in relationships between securities yields and yield-surrogates, Journal of Financial Economics, 6, 103-126.

Balvers, R.J., Cosimano, T.F., McDonald, B., 1990, Predicting stock returns in efficient markets, The Journal of Finance, 45, 1109-1128.

Belmonte, M.A.G., Koop, G., Korobilis, D.,2013, Hierarchical shrinkage in time varying parameter models,Journal of Forecasting, ISSN 0277-6693 (In press).

Campbell, J. Y., 1987, Stock returns and the term structure", Journal of Financial Economics, 18, 373-399.

Chapra, M. U., 2008, The global financial crisis: can Islamic finance help minimize the severity and frequency of such a crisis in the future? Paper presented at the Forum on the Global Financial Crisis, Islamic Development Bank, Jeddah.

Dewi, M., Ferdian. I. R., 2010, Islamic finance: A therapy for healing the global financial crisis, http://www.iefpedia.com/english/wp-content/uploads/2009/10/Islamic-Finance-A-Therapy-forHealing-the-Global-Financial-Crisis.pdf

Diebold, F.X., Mariano, S., R, 1995, Comparing predictive accuracy. Journal of Economics and Business Statistics, 13, 253-263.

Dridi, J., Hassan, M., 2010,The effects of global crisis on Islamic and conventional banks: A comparative study.International Monetary Fund Working Paper No, 10/201.

Fama, E. F. and Schwert, G.W. 1977, Asset returns and inflation, Journal of Financial Economics, 5(2), 115-146. 
Fama, E. F., 1981, Stock returns, real activity, inflation, and money, American Economic Review 71,545-565.

Fama. E. F., French, K. R., 1988a, Permanent and temporary components of stock prices. Journal of Political Economy 96.246-273.

Fama. E. F., French, K. R., 1988b. Dividend yields and expected stock returns. Journal of Financial Economics 22, 3-25.

Guidolin, M., Hyde, S., McMillan, D., Ono, S., 2009, Non-linear predictability in stock and bond returns: When and where is it exploitable?, International Journal of Forecasting, 25(2), 373-399.

Guidolin, M., Hyde, S., McMillan, D., Ono, S. 2010, Does the macroeconomy predict U.K. asset returns in a nonlinear fashion? Comprehensive out-of-sample evidence, Working Papers 2010-039, Federal Reserve Bank of St. Louis.

Hakim, S. and Rashidian, M., 2002, Risk and return of Islamic stock market indexes. Paper Presented at the $9^{\text {th }}$ Economic Research Forum Annual Conference in Sharjah, U.A.E. on October 26-28.

Hammoudeh, S., Jawadi, F. and Sarafrazi, S. 2013. Interactions between conventional and Islamic stock markets: a hybrid threshold analysis. Mimeo, Drexel University, PA, USA.

Hodrick, R., 1992, Dividend yields and expected stock returns: alternative procedures for inference and measurement. Review of Financial Studies, 5, 357-386.

Koop, G. and Korobilis, D., 2012, Forecasting inflation using dynamic model averaging, International Economic Review, 53(3), 867-886.

Kothari, S.P., Shanken, J., 1997, Book-to-market, dividend yield, and expected market returns: A time-series analysis, Journal of Financial Economics 41, 169-203.

Lintner, J., 1975, Inflation and security returns, Journal of Finance, 30, 259-280

McCracken, M.W., 2004, Asymptotics for out-of-sample tests of causality. University of Missouri-Columbia, Manuscript.

Menzly, L., Santos, T., Veronesi, P., 2004, Understanding predictability, Journal of Political Economy, 112(1), 1-47.

Pontiff, J., Schall, L. D., 1998, Book-to-market ratios as predictors of market returns Journal of Financial Economics, 49(2), 141-160.

Rapach, D., Wohar, M.E., 2006, In-sample vs. out-of-sample tests of stock return predictability in the context of data mining, Journal of Empirical Finance, 1, 231-247.

Rapach, D., Wohar, M.E and Rangvid, J., 2005, Macro variables and international stock return predictability, International Journal of Forecasting, 21, 137-166. University of California at Los Angeles. 
Rapach, D., Zhou, G., 2013, Forecasting stock returns in Elliott, G. and Timmermann, A. (eds), Handbook of Economic Forecasting, 2A: 328-383.

Rozeff, M. S., 1984, Dividend yields are equity risk premiums, Journal of Portfolio Management, 68-75.

Shiller, R. J., 1984, Stock prices and social dynamics, Brookings Papers on Economic Activity, 2, 457-498.

Schwert, G., W., 1990, Stock returns and real Activity: A century of evidence The Journal of Finance,45(4),1237-1257.

Vizcaino, B. 2013, ICD launches numerical studies of Islamic finance.

http://en-maktoob.news.yahoo.com/icd-launches-numerical-studies-islamic-finance$\underline{073741590-- \text { sector.html }}$

West, K.D., 1996, Asymptotic inference about predictive ability. Econometrica, 64, 10671084. 


\section{Appendix}

\section{Table A1: Definitions and Sources of Variables Used in Predicting DJIM}

The $z_{i, t}$ variables are all transformed to be approximately stationary according to the following codes: 1 - No transformation (levels), $x_{i, t}=z_{i, t} ; 2$ - First difference; $x_{i, t}=z_{i, t}-z_{i, t-1} ; 3$ - Logarithm, $x_{i, t}=\log z_{i, t} ; 4-$ First difference of the logarithm; $x_{i, t}=\log z_{i, t}-\log z_{i, t-1}$ (Koop \&Korobilis, 2012).

\begin{tabular}{|c|c|c|c|}
\hline VARIABLE & TCODE & $\begin{array}{l}\text { DESCRIPTION } \\
\left(z_{i, t}\right)\end{array}$ & SOURCE \\
\hline KCFSI & 1 & $\begin{array}{l}\text { Kansas City } \\
\text { Financial Stress } \\
\text { Index }\end{array}$ & Kansas City's Federal Reserve Bank, \\
\hline PUI & 4 & $\begin{array}{l}\text { Policy Uncertainty } \\
\text { Index }\end{array}$ & http://www.policyuncertainty.com/index.html \\
\hline DSPREAD & 1 & Default Spread & Saint Louis's Federal Reserve Economic Data \\
\hline IP & 4 & $\begin{array}{l}\text { Industrial } \\
\text { Production }\end{array}$ & Saint Louis'sFederal Reserve Economic Data \\
\hline NTWUDI & 5 & $\begin{array}{l}\text { Nominal Trade } \\
\text { Weighted US } \\
\text { Dollar Index }\end{array}$ & $\begin{array}{l}\text { International Financial Statistics (IFS) of the } \\
\text { International Monetary Fund (IMF) }\end{array}$ \\
\hline TBILL & 2 & Treasury Bill Rate & IFS of the IMF \\
\hline SP500 & 5 & $\begin{array}{l}\text { Standard \& Poor's } \\
500\end{array}$ & $\begin{array}{l}\text { http:www.blomberg.com/markets/stocks/world- } \\
\text { indexes/ }\end{array}$ \\
\hline INF & 1 & Inflation & $\begin{array}{l}\text { Own calculation based on the Consumer Price } \\
\text { Index on all items obtained from the Federal } \\
\text { Reserve Economic Data, Saint Louis }\end{array}$ \\
\hline SPEU & 5 & S\&P Europe Index & $\begin{array}{l}\text { http:www.blomberg.com/markets/stocks/world- } \\
\text { indexes/ }\end{array}$ \\
\hline SPAS50 & 5 & S\&P Asia 50 & $\begin{array}{l}\text { http:www.blomberg.com/markets/stocks/world- } \\
\text { indexes/ }\end{array}$ \\
\hline OP & 2 & Oil Price & IFS of the IMF \\
\hline EMPL & 5 & Employment & Saint Louis's Federal Reserve Economic Data. \\
\hline UMCSENT & 5 & $\begin{array}{l}\text { University of } \\
\text { Michigan } \\
\text { Consumer } \\
\text { Sentiment }\end{array}$ & Federal Reserve Bank, Kansas City \\
\hline VIX & 4 & Volatility Index & $\begin{array}{l}\text { http:www.blomberg.com/markets/stocks/world- } \\
\text { indexes/ }\end{array}$ \\
\hline
\end{tabular}



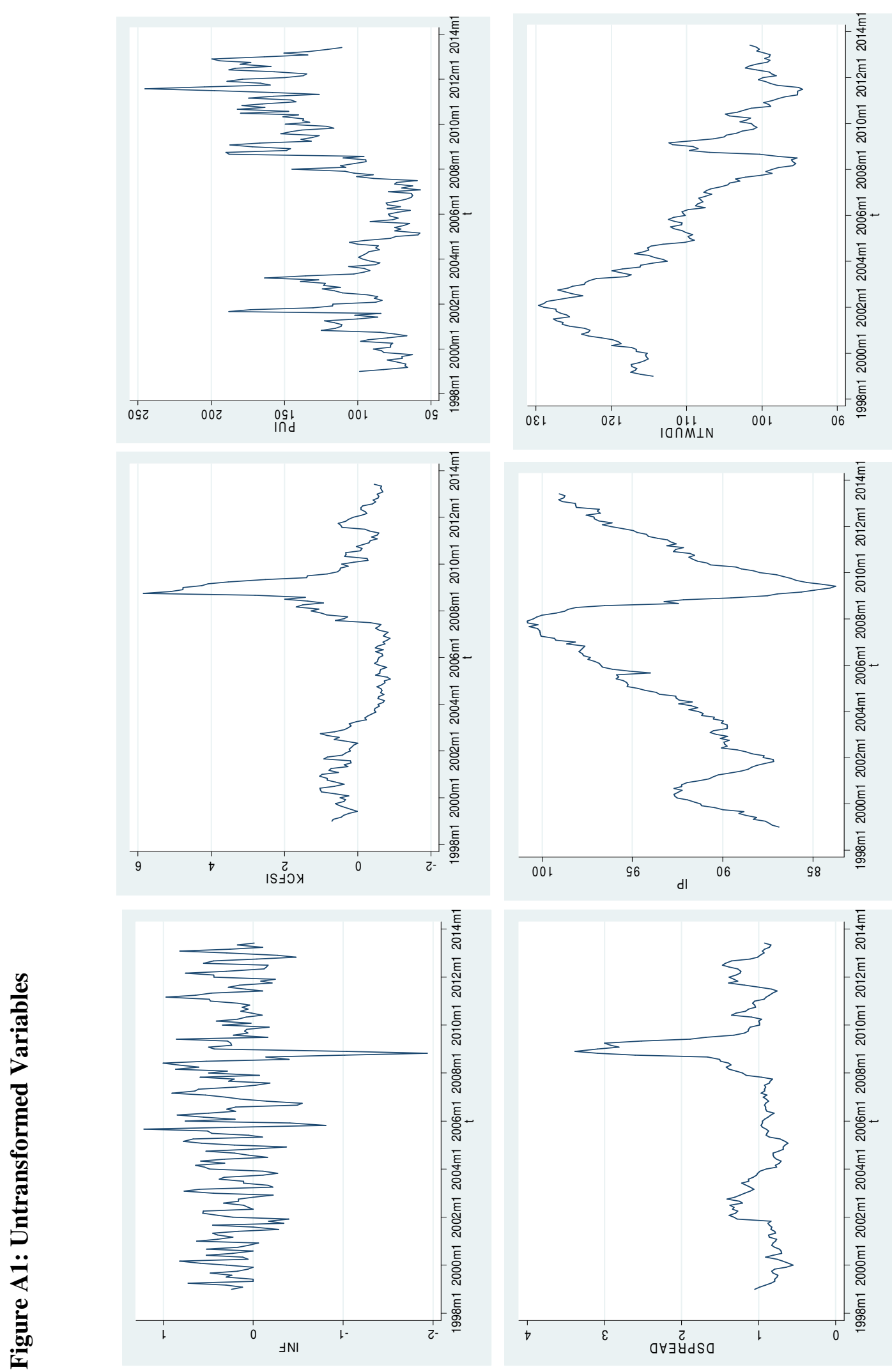

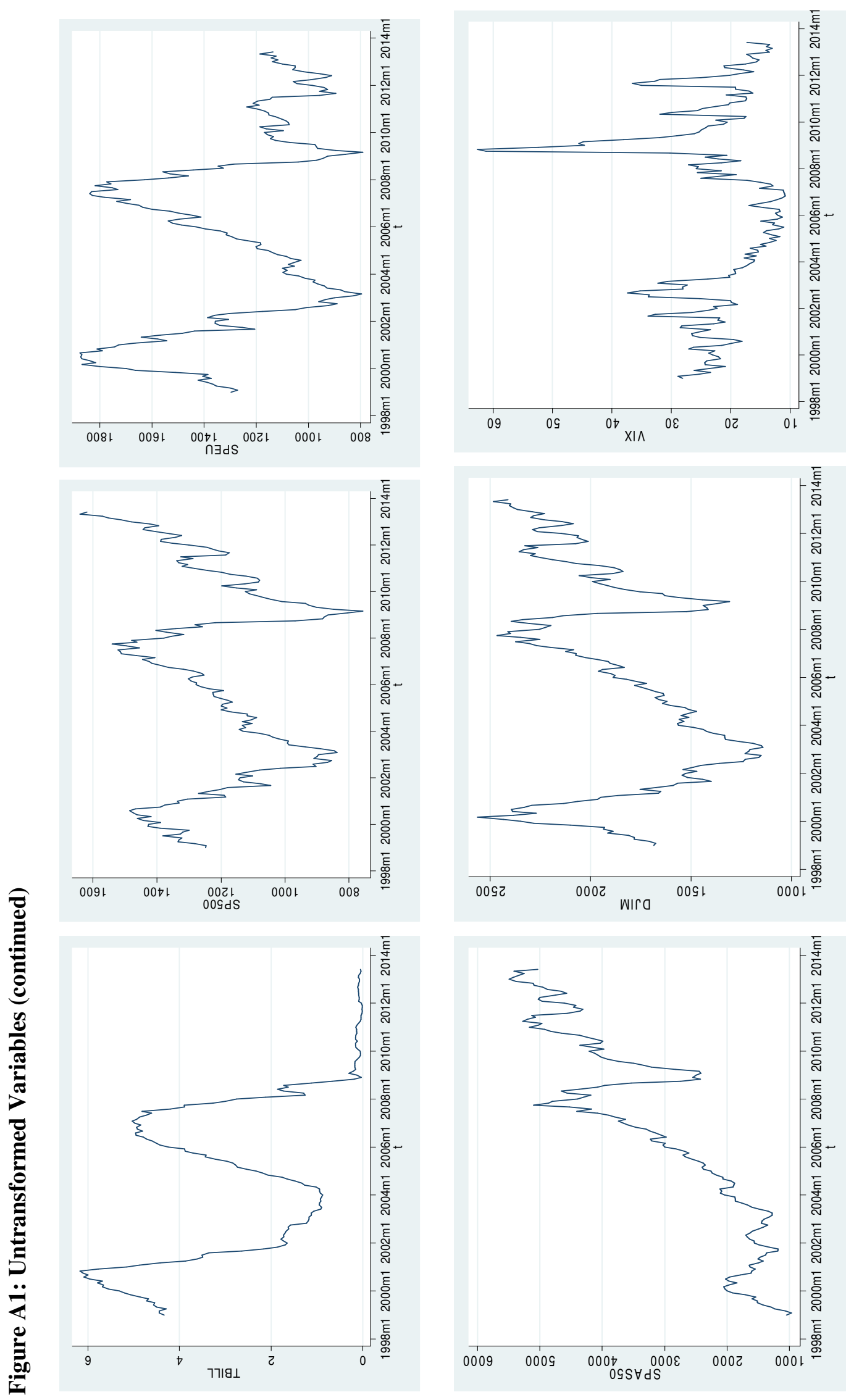

N 


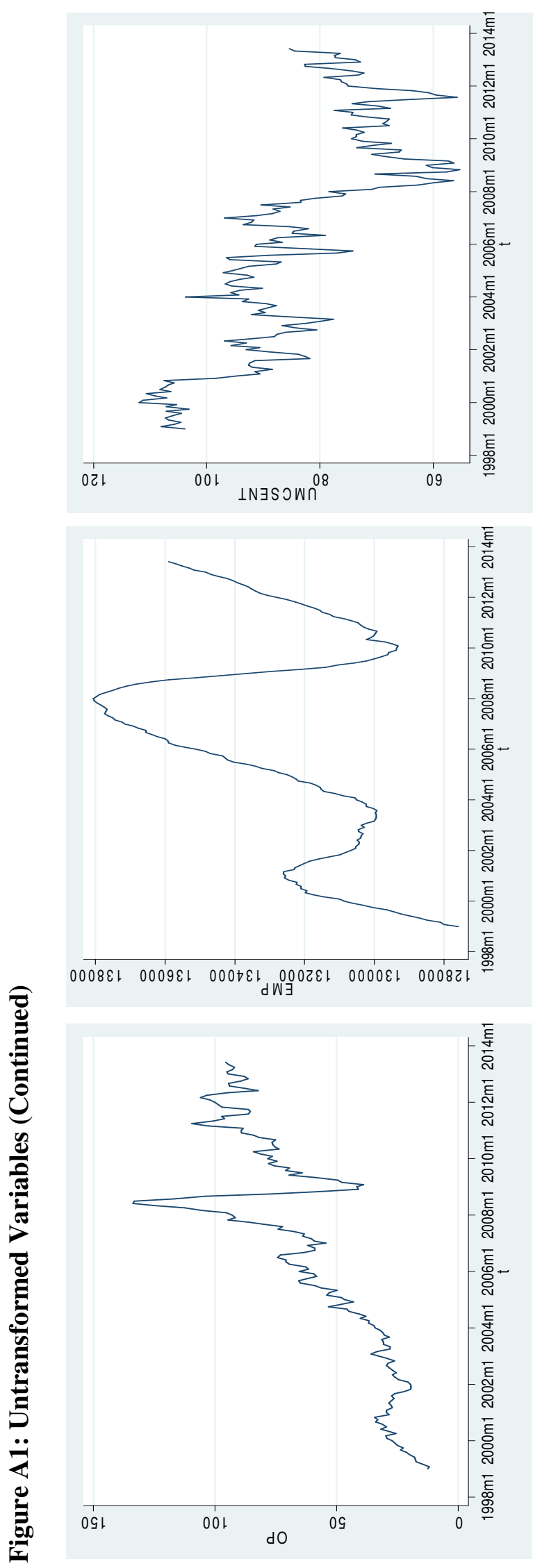



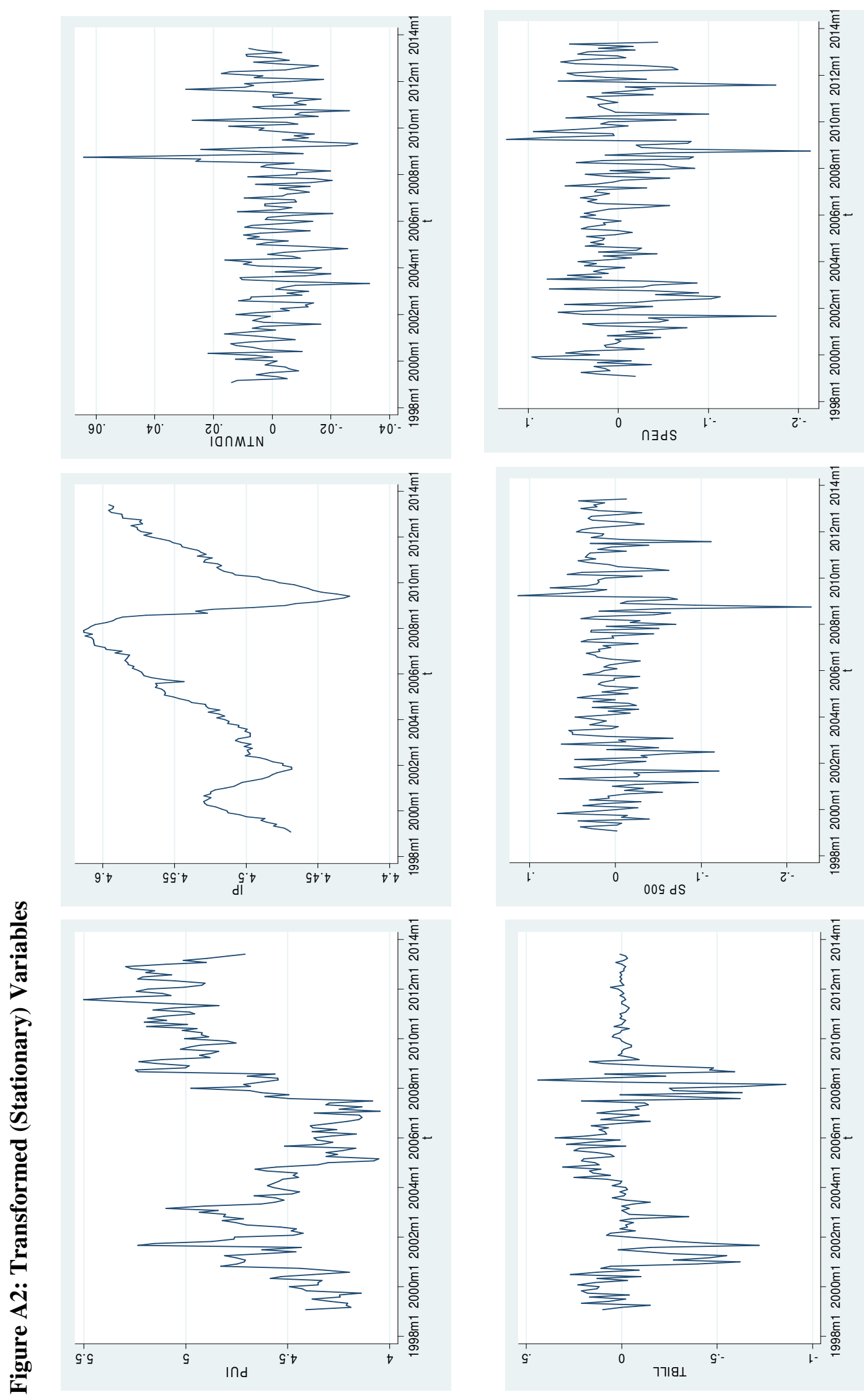

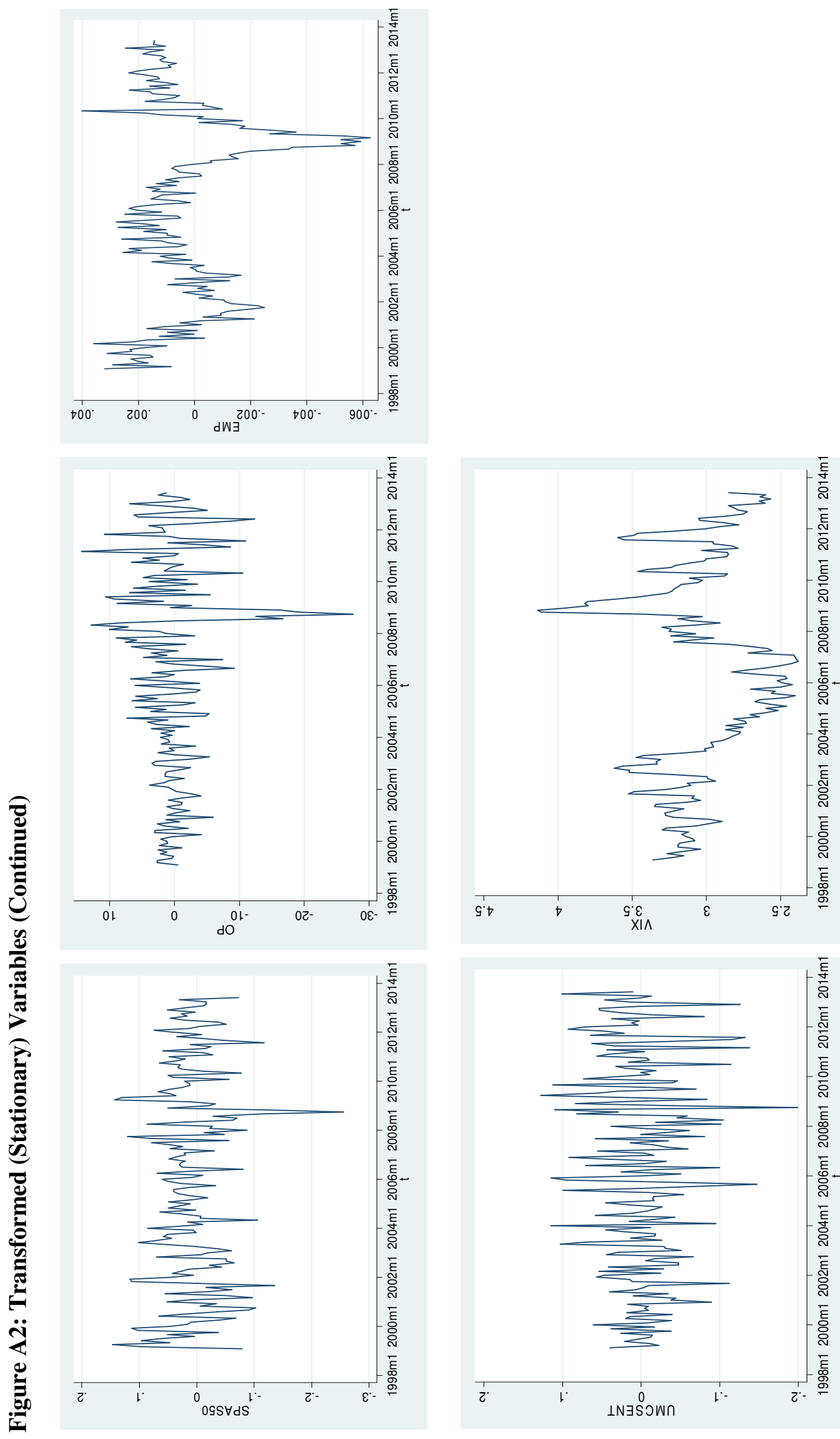
Table A2-Forecast Combination and Multivariate Forecasts:

\begin{tabular}{lrrrrr}
\hline & & & MSE & \\
\cline { 2 - 6 } Models & H=1 & H=3 & H=6 & H=9 & H=12 \\
\hline Mean & 1.0160 & 1.0170 & 1.1000 & 1.1390 & 1.0960 \\
Median & 1.0080 & 1.0010 & 0.9962 & 1.0110 & 1.0100 \\
Trimmed mean & 1.0080 & 1.0100 & 1.0740 & 1.0910 & 1.0440 \\
DMSFE (delta=1.0) & 1.0170 & 1.0170 & 1.0990 & 1.1430 & 1.1550 \\
DMSFE (delta=0.9) & 1.0160 & 1.0150 & 1.1200 & 1.2260 & 1.1070 \\
C (2,PB) & 1.0240 & 1.0180 & 1.2190 & 1.1690 & 1.1790 \\
C (3,PB) & 1.0320 & 1.0740 & 1.3520 & 1.3830 & 1.4060 \\
PC (IC_P3) & 1.1150 & 1.5000 & 1.6870 & 2.5690 & 3.1910 \\
BA Model & 1.2050 & 2.2220 & 3.6540 & 5.4260 & 5.6800 \\
\hline Factors models & 1.0921 & 1.1290 & 1.1959 & 1.2587 & 1.2237 \\
TVP no lasso & 2.2659 & 7.7660 & 31.1691 & 43.9518 & 52.7670 \\
Lasso and TVP & 1.1867 & 7.9301 & 27.9560 & 45.4036 & 55.4535 \\
Lasso but no TVP & 1.0562 & 4.7922 & 12.1187 & 18.6583 & 24.9219 \\
No lasso no TVP & 1.2273 & 1.2400 & 1.6538 & 2.0769 & 1.2963 \\
DMA $(\alpha=\lambda=0.99)$ & 1.2192 & 1.1846 & 1.6847 & 2.0043 & 1.3050 \\
DMS $(\alpha=\lambda=0.99)$ & 1.1740 & 1.1846 & 1.0721 & 1.5883 & 1.0440 \\
BMA & 1.2192 & 1.1846 & 1.6847 & 2.0421 & 1.2677 \\
\hline \hline
\end{tabular}

Notes: The entries are the average ratio of the combined method MSEs relative to the AR benchmark MSE so that a ratio above unity (as it is the case) indicates that the combined method forecast is less accurate than the AR benchmark forecast in terms of MSE. All forecasts are recursive and MSEs are computed over the period 2007:1-(2013:6-h). The forecast mnemonics are:

- Mean: Average of individual forecast at date $t$;

- Median: Median of individual forecast at date $\mathrm{t}$;

- $\quad$ Trimmed mean: Trimmed mean of individual forecast at date t, 5 percent symmetric trimming;

- DMSFE (delta): Combined forecast where the Discount Mean Square Forecast Error criterion is used to determine the weights of the individual forecast at date $\mathrm{t}$; delta being the discount factor;

- $\quad \mathrm{C}(\mathrm{K}, \mathrm{PB})$ : Cluster combining method forecast with $\mathrm{K}$ the number of clusters;

- PC (IC_P3): Forecasts from regression onto principal components of the panel of forecasts; number of principal components determined by IC_P3 information criteria proposed by Bai and $\mathrm{Ng}$ (2002);

- $\quad$ A 60 month holding period is used for the DMSFE and cluster combination methods;

- $\quad$ BA refers to the Bootstrap Aggregating, popularly known as bagging model;

- $\quad$ Factor model: 3 factors (chosen based on the IC_P3) used together in equation (1) ;

- $\quad$ TVP no lasso: Time Varying Parameters model without Least Absolute Shrinkage Selection Operator;

- $\quad$ LASSO and TVP: Least Absolute Shrinkage Selection Operator on both constant and Time Varying Parameters;

- $\quad$ LASSO no TVP: Least Absolute Shrinkage Selection Operator and Constant parameters;

- DMA: Dynamic Model Averaging where $\alpha$ is the forgetting factor for the state equation for the model and $\lambda$ is the forgetting factor for the state equation for the parameter;

- $\quad$ BMA: Specific form of DMA limited to static models with parameter uncertainty;

- DMS: Dynamic Model Selection; and

- $\quad$ The reader is referred to Belmonte et al. (2013) and Koop and Koroboris (2012) for further details on the time-varying models. 